\title{
Abstracts
}

\section{Moral Economy and Old Age}

\section{Lorna Warren}

Fred Twine, Citizenship: opportunities, rights and routes to welfare in old age. Journal of Social Policy, 21, 2 ( 1992 ), 165-75.

This is the first of three articles all linked by the theme of dependency and the welfare of older people. In it, Fred Twine is concerned to distinguish between 'rights' and 'opportunities' which, he argues, have been confused by commentators (notably T. H. Marshall) within their notion of civil rights with subsequent implications for our understanding of routes to welfare over the life course.

Twine uses the example of employment to illustrate the distinction. "With over 2.5 million persons unemployed", he states, "a contract of employment is better understood not as a 'right' but as an 'opportunity'. There is no right to employment" (p. I66). Thus, Twine replaces 'civil right' with the term 'civil opportunity'. Taking a life course perspective on labour market participation and contracts, he then goes on to show how, especially in light of the man-made nature of an increasing number of states of dependency experienced by people in industrial society, an 'opportunity' is a less secure route to welfare in old age than a 'right'. This is chiefly because schemes, such as the Occupational Pension Scheme (OPS), which provide pensions through the civil opportunity of a labour contract cannot incorporate the social costs of social change. Wholly labour market dependent, they do not make provision for contribution loss arising from spells of unemployment or caring activity, for instance. The State Earnings Related Pension Scheme (SERPS) may be far from being an ideal alternative, but $T$ wine believes it has greater potential for providing a social right to an adequate pension since a person remains in the scheme no matter how often their job changes and they are credited with a basic contribution. Women, who are on the whole more vulnerable to periods of unemployment than are men, are particularly benefited by the plan which, moreover, incorporates allowances for the caring and nurturing activities which still chiefly affect their lives.

The government has promoted support for a civil opportunity route to pensions in old age, tempting people with the promise of enormous tax subsidies and diverting their attention away from consideration of 
life course employment experiences and the long term problem of poverty in old age. Twine ends his article by calling for the exercise of political rights, stimulated through wide ranging political debate, to establish a social right.

Meredith Minkler and Thomas R. Cole, The political and moral economy of aging: not such strange bedfellows. International fournal of Health Services, 22, I (1992), I I 3-1 24.

Pension schemes and their evolution are one of the areas (along with the 'senior revolt' against catastrophic coverage and the allocation of health resources) explored by Meredith Minkler and Thomas Cole in their examination of the conditions, experiences, treatment and health of older people in the United States. Drawing from Marx's notion of a 'morality of emancipation', their concern is to develop E. P. Thompson's concept of moral economy as a useful complement to political economy in enriching our understanding of ageing.

The work of Marx may seem a strange place from which to begin such a task given that the later Marx saw his critique of capitalism as scientific rather than moral. Minkler and Cole face this paradox by pointing out Marx's distinction between the ideological morality of Recht-a form of false consciousness-and the true morality of emancipation. The former refers to aspects such as justice, fairness, rights and obligation which govern and stabilise capitalist social relations while claiming to protect the 'rights of man' in general. The latter is based on an imagined harmony of social unity and individual selfdevelopment. Rather than rejecting concerns with the morality of Recht, the authors suggest that the moral economy, understood as part of an expanded conception of Recht, can help guide future work in the political economy of ageing.

It is E. P. Thompson's definition of the concept of moral economy as collectively shared assumptions defining norms of reciprocity with which Minkler and Cole operate. Thompson used the concept to uncover the shared moral norms that empowered artisans, peasants, and labourers who rioted in response to soaring food prices in the late eighteenth and early nineteenth centuries. Yet, historical investigation of Recht, in this sense of moral economy is still in its infancy while contemporary applications have tended to concentrate on studies of premarket societies in developing societies suggesting a false dichotomy between moral and market economy.

Minkler and Cole argue for employment of the concept in the examination of moral conflict within the market economy in advanced 
industrialised nations, citing instances of how this has been done with successful results in the field of ageing. They note, for example, how several analysts have looked at pension systems, resource allocation questions and other social policy considerations within a life course perspective revealing the importance of implicitly embedded norms of reciprocity, continuity in standards of living, and 'deserving' and 'undeserving' elderly and poor people. Moreover, while such norms have typically been held primarily to underlie older workers' goal of achieving a pension system, they have also had important social control functions that served the interests of the dominant class. The institution of retirement in advance of physiological necessity enabled employers to rid themselves of their most expensive workers, created and reinforced dependence and reduced dangerously high levels of unemployment in young men. Such social control functions have traditionally been examined by the political economy yet, as the example shows, the combined use of moral economy perspectives may offer much fuller explanations.

In turn, a more thoughtful integration of the two perspectives leads to a changed emphasis on goals for an ageing society where, according to Minkler and Cole, mass longevity has created a new abundance of later life that is plagued by the absence of vital cultural meaning. The authors still see the creation of a just distribution of resources between and within age groups as central but they also call for attention to be paid to quality of life issues in education, work, productivity and health care at each stage of the life course. In other words, they appeal to the ideals of Marx's morality of emancipation that free time be spent for genuine human development within a context which affirms the intimate interdependence of generations.

Jon Hendricks and Cynthia A. Leedham, Toward a political and moral economy of aging: an alternative perspective. International Journal of Health Services, 22, I, (1 992), 125-1 37 .

Jon Hendricks and Cynthia Leedham are concerned with the question of how emancipation - or specifically, in this case, empowerment of elderly people - is to come about. To this end, in their article, they propose a conceptual framework which borrows from Gramsci's notion of hegemony exploring the implications of its application for health and income maintenance policies.

The piece opens with a discussion of the problem of the individualstructure dialectic for gerontological theory. Broadly speaking, at opposite ends of the extreme, political economy focusses on social 
structure and location - including world and national economies, the state, labour market conditions, race, gender and age divisions - while social psychology concentrates on individual adaptation to the circumstances of ageing - encompassing modes of action, consciousness and selfhood, autonomy and control, and intentionality. The need, the authors claim is for 'a reciprocal perspective that can capture how societal factors inhibit or enhance empowerment and the ways in which individuals affect social structure by challenging or submitting to situational constraints' (p. I 26), and hegemony offers just such a framework.

Hegemony comprises taken-for-granted assumptions underlying active consent to existing forms of leadership and social organisation. In certain states, where active consent is based on a misapprehension of the situation - a process likened to the Marxian idea of false consciousness - oppression may arise. Thus elderly people are made dependent through the normalisation of their exclusion from the economic mainstream. What Hendricks and Leedham aspire to is Gramsci's vision of a new moral and philosophical leadership 'a state of hegemony to which people could give full and informed consent because the policies to which it gives rise are in their own best long-term interests' (p. I 29).

It is at this point that the authors introduce the key concept of moral economy which, they state, is central to the idea of emancipatory hegemony. Like Minkler and Cole, they too define moral economy as the shared assumptions about norms of reciprocity going on to distinguish between two ideal types: moral economy grounded in usevalue and moral economy grounded in exchange-value. They believe that there has been a shift in Western society in recent years away from the former to the latter, or from the goal of meeting human needs to that of economic profitability. The result for older people has been their devaluation since the structure of the labour force excludes most from productive economic activity and attention is not given to their social activities outside this sphere which may include voluntary and caring work. Moreover, the young and middle-aged are prevented from realising their own interest in creating a viable system of income security for their own old age.

What Hendricks and Leedham wish for is the (re)adoption of a moral economy grounded in use-value which is concerned with the public good and sees citizens as active moral agents in the social policy progress. The challenge lies in the balancing of the needs and visions of one's own generation and those of others within existing resource constraints. To turn, once again, to the example of income maintenance 
policy, this would mean reconciling provision of a decent minimum income for all with sustaining a viable economy, productive enough to meet social needs. Policy would necessarily address the overall structure of the labour market, ageism and other forms of discrimination in employment, and opportunities for education and job retraining throughout life. For the authors, this would involve encouraging labour force participation past the current retirement age as part of the aim to 'maximise functioning and tap the skills and resources (older people) have to offer' (p. I34).

\section{COMMENT}

These three articles are linked by the general desire to expand our understanding of the dependency of older people. Their concern is with the analytical frameworks which we employ in our investigations. They aim to address the degree of inequality experienced by older people and all, therefore, have implications for social policy, especially for the provision of pensions in old age. Where they differ is in their starting points and the specific focus of their arguments.

Twine locates the impetus for his paper as coming from the revival of debate over concepts of citizenship. This is no post-modernist discussion, however, for his major objective is to examine what he sees as a confusion of terminology within that debate. He argues for a life course approach to social dependence but it is limited to the arena of people's labour market experience.

Minkler and Cole and Hendricks and Leedham share the laudable desire to go beyond simple structural accounts of dependency offered by political economy and to explore, in this case through the complementary concept of the moral economy, the shared norms and values in which economic systems are grounded. Minkler and Cole acknowledge a humanistic drive. They offer some interesting examples of the varied use of moral economy in the study of ageing but the article they have written is basically a Marxian case for such an approach. While Hendricks and Leedham support the goal of emancipation, their spur is to move further still, beyond mere critique, to find a grounding for a model of social organisation which makes empowerment possible. Application of the notion of 'true hegemony' may be a novel approach within the field of social gerontology if the call for a dialectical view of ageing is not.

If, after reading the articles, I am left with a vague aftertaste, it comes from the feeling of old arguments being rehashed. Minkler and Cole talk of 'cultural questions' (p. I I4) but they do not pursue this 
line. Yet commitment to a more holistic approach in the understanding of cultural questions has long been a central tenet of social anthropologists who are increasingly applying their skills in the gerontological sphere to address policy-related issues. And, if we need to know how to encourage people to exercise their political rights (Twine p. I 74), it seems likely that they will have pertinent suggestions.

Department of Sociological Studies, University of Sheffield

Medicine in Society

\section{J. Grimley Evans}

N. J. Dudley and E. Burns. The influence of age on policies for admission and thrombolysis in coronary care units in the United Kingdom. Age and Ageing, 21 (1992), 95-98.

This paper reports a national survey of the 175 consultants in charge of coronary care units in the United Kingdom at the beginning of 1991 . Coronary care units are specially equipped hospital wards staffed by cardiologists and specially trained nurses and are responsible for looking after patients admitted with heart attacks. The 24 hours after a heart attack are the most dangerous and one of the most important functions of the coronary care unit staff is to prevent a patient's heart stopping and to restart it if necessary. Of the 134 units whose consultants responded to the survey, 19\% operated an admissions policy which excluded patients above a specified age. Two units had an upper age limit at 65 years, 7 at age 70,14 at 75 and 2 at 80 . Recently it has been shown that injections of a drug that dissolves clots in the arteries to the heart, so-called thrombolytic therapy, increases the survival of people who have suffered a heart attack. At present the treatment has to be given early after the attack and in a specialist unit with skilled staff and continuous electronic monitoring of the heart beat. Fifty four units $(40 \%)$ operated an upper age limit for thrombolytic therapy: two at age 65 , eight at 70,22 at 75 , ten at 80 , ten at higher ages and two at unspecified ages.

\section{COMMENT}

In I99 I the Royal College of Physicians published a report on cardiological interventions in elderly patients which stated that, 'arguments for restricting treatment because of age alone can no longer be sustained on clinical grounds'. There is nothing to suggest that older 